\title{
Preditor de Sucesso Cinematográfico
}

\author{
André Luiz F. de Albuquerque Juliana V. Valério Luan B. Garrido \\ andreluiz90@ig.com.br, juvianna@dcc.ufrj.br, lbgarrido89@gmail.com \\ Depto de Ciências de Computação, IM, UFRJ, \\ 21941-916, Rio de Janeiro, RJ
}

\section{RESUMO}

A recente facilidade da compra e venda de itens no geral, como produtos e serviços, acirrada pela maior pluralidade de empresas operantes para um mesmo público, fez com que essas tivessem maior preocupação quanto a qualidade e o marketing dos produtos que oferecem.

Porém, é sabido que o gasto em maior durabilidade ou robustez de um produto ou serviço nem sempre está atrelado a uma maior vendagem ou satisfação dos usuários. Essa assertiva torna-se mais visível quando tratamos da indústria cultural, principalmente na indústria cinematográfica.

Filmes com alto investimento, tais como atores famosos, altos custos de produção ou estória apelativa podem muitas vezes não obter a receita desejada. Um exemplo é o filme Town \& Country com custo de produção de $\$ 90,000,000$ e receita agregada mundial até o final de seu ano de lançamento de $\$ 10,372,291$ [1], valores que indicam não foi possível recuperar ao menos $15 \%$ do investimento.

Este trabalho visa, através de um sistema de equações diferenciais ordinárias insipirado no modelo SIR [3], e da extração de dados em redes sociais, analisar o comportamento dos espectadores perante ao lançamento de um trailer e da troca de informações sobre esse, com o objetivo de quantificar o saldo final entre pessoas que decidiriam ir ao cinema assistir ao filme e pessoas que decidiram por não fazê-lo, evitando um custo desnecessário para as produtoras.

A partir de uma população constante $P$, o modelo considera, durante o período de cartaz do filme, tanto a influência das pessoas que entram em contato com seus amigos quanto propriedades que estão intrinsicamente ligadas ao filme, como direção ou elenco - chamadas aqui de fatores intrínsecos. O modelo fica descrita da seguinte forma:

$$
S+V+N=P
$$

Onde os conjuntos $S, V, N$ representam, respectivamente, as pessoas ainda suscetíveis a tomar uma decisão, as que decidiram por assistir ao filme e as que não o assistiram.

$$
\begin{gathered}
\frac{d S}{d t}+\frac{d V}{d t}+\frac{d N}{d t}=0 \\
\frac{d V}{d t}=\gamma s \operatorname{Ip} L+\rho_{t} S \\
\frac{d N}{d t}=\gamma \operatorname{sIn}(D+N) \\
\frac{d L}{d t}=\text { gostou } \frac{d V}{d t} \\
\frac{d D}{d t}=(1-\text { gostou }) \frac{d V}{d t}
\end{gathered}
$$

O conjunto $\mathrm{V}$ pode ser decomposto em pessoas que gostaram do filme $(L)$ e que não gostaram $(N)$. As variáveis $I p$ e In representam a força de convencimento média que cada indivíduo desses grupos possuem, 
atualizados pela majoritariedade que seu grupo possui no ambiente (Comportamento de Rebanhos [2]) e gostou é um fator aleatório que indica a probabilidade de uma pessoa gostar ou não do filme.

Ao final das execuções dos sistema e a devida construção de intervalos de confiança, por se tratar de equações com variáveis aleatórias, é possível construir gráficos que determinam o fluxo de pessoas pelos conjuntos destacados.

O gráfico abaixo representa a simulação do filme Grown Ups 2, lançado em 2013:

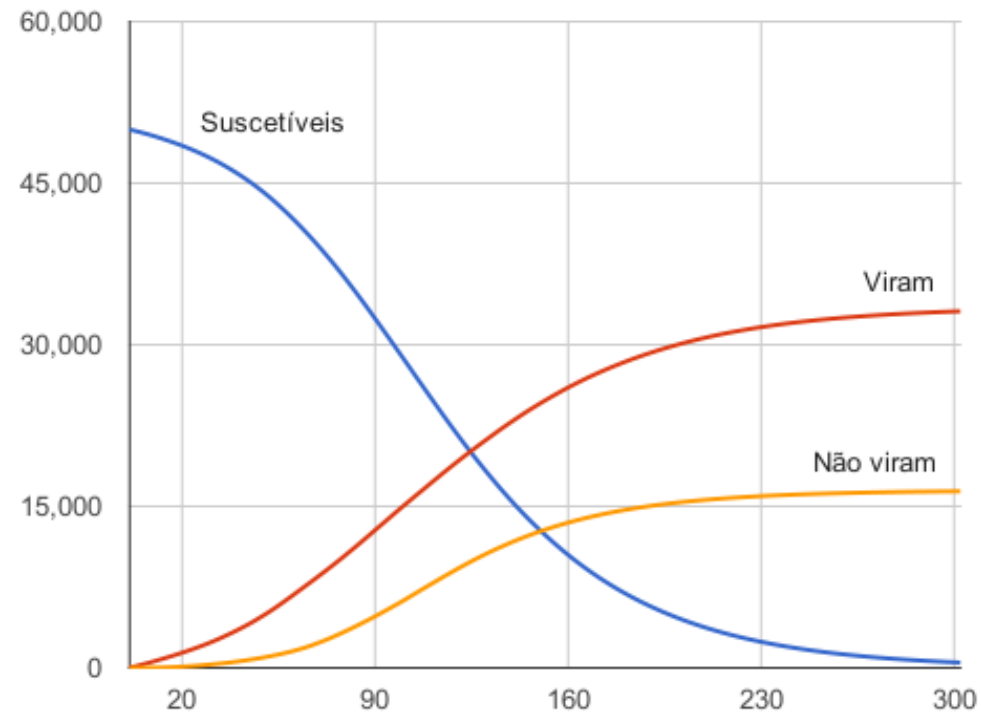

Figura 1: Resultado para Grown Ups 2

Este resultado indica que o saldo entre os grupos $V$ e $N$ foi positivo, tornando promissora a realização completa do filme para a produtora. A quantidade final do grupo $V$ quando multiplicada pelo valor médio dos ingressos dos cinemas fornece às empresas os números que serão utilizados para a definição da viabilidade do filme.

Foram realizadas várias simulações com diversos filmes e os resultados foram satisfatórios. Mesmo para casos de fracasso o algoritmo foi capaz de classificá-los. Será dado um prosseguimento para que o simulador possa ser efetivamente usado.

Palavras-chave: Preditor, Indústria Cultural, EDO, Extração de dados

\section{Referências}

[1] Box Office Mojo, http://www.boxofficemojo.com/movies/?id=townandcountry.htm, Fevereiro, 2014

[2] Iain D. Couzin, et al, Uninformed individuals promote democratic consensus in animal groups, Science Magazine, Reports section, 334 (2011), pp. 1578-1580

[3] William O. Kermack, Anderson G. McKendrick, A contribution to the mathematical theory of epidemics, Proceedings of the Royal Society A, London, 115 (1927), pp. 700-721 